\title{
Competing Paradigms: The Dilemmas and Insights of an ELT Teacher Educator
}

\author{
Aysun Yavuz \\ Department of English Language Teaching, Faculty of Education \\ Çanakkale Onsekiz Mart University, Çanakkale/Turkey \\ Tel: 90-286-217-1303Ｅ-mail: yavuzaysun@hotmail.com
}

Received: August 12, 2011

Accepted: September 22, $2011 \quad$ Published: February 1, 2012

doi:10.5539/ies.v5n1p57

URL: http://dx.doi.org/10.5539/ies.v5n1p57

\begin{abstract}
In this paper, the writer discusses the philosophical underpinnings of the two dominant research methods in social sciences; quantitative and qualitative paradigms. The natures of two paradigms are quite different so this leads many researchers to discuss these issues in a comparative way. This paper tackles the knowledge and understanding of quantitative and qualitative paradigms, their nature, advantages, disadvantages, assumptions, criticisms, and the possibility of linking two paradigms. Issues of validity, reliability, objectivity, and generalisation are also investigated from two distinctive perspectives of paradigms. Finally, the conclusion and suggestions are given at the end of the paper. The novice researchers who are in dilemmas about making decisions about their research designs would potentially find the discussions useful.
\end{abstract}

Keywords: Qualitative paradigm, Quantitative paradigm, Validity, Reliability, Objectivity, Generalisation

\section{Introduction}

The purpose of this study is to discuss the philosophical underpinnings of the two dominant research methods in social sciences; quantitative and qualitative paradigms. There is no doubt that the philosophical bases of the two paradigms are quite different so this distinctive nature leads many researchers to discuss these issues in a comparative way. I believe that each philosophy has its own advantages and disadvantages deriving from their distinct nature and both of them should be recognised and respected. Silverman (1993) stated this idea very briefly:

"...One of the least fruitful questions one can ask a sociologist is: 'To what school of social science do you belong?'.... For, of course, there are no principled grounds to be either qualitative or quantitative in approach. It all depends upon what you are trying to do" (p. 22)

So research topic and the most suitable way of data collection determine one's approach. It is also important to remember one of the most important similarities between two paradigms is that they both generate knowledge, which, of course, take different forms and procedures. As Patton cited in Goodwin and Goodwin (1996), these different types of knowledge may appeal to different audiences and can be used as complementary. On the other hand, Bogdan and Biklen (1992) noted that, especially novice researchers, trying to combine quantitative and qualitative design, experience a big headache and their work does not meet the criteria in either approach.

I think that a good researcher has the understanding and ability to conduct high-quality multiple-method research if there is a need depending on the research topic. Deriving from this belief, after giving a brief general and historical background I will discuss the philosophical underpinnings, nature and some features, assumptions and criticisms of the paradigms of quantitative and qualitative.

I will also discuss the idea of linking two approaches related to my opinion stated at the beginning of paragraph. It is of course, crucial to mention the general and historical perspectives, different natures and criticisms of two dominant paradigms before discussing the logic of combining them together since one cannot understand the rationale of this possibility - if it is necessary - without knowing the distinct natures of the mentioned paradigms.

\section{Philosophical Underpinnings of the Quantitative and Qualitative Paradigms}

\subsection{A General and Historical Perspective}

Quantitative Paradigm has long been recognised and practised as the dominant paradigm until the mid 1980s in social sciences. Lincoln and Guba (1985) point out that there are three quantitative paradigm eras, which are; the 
pre-positivist, the positivist, and the post-positivist. They argue that the pre-positivist era is the longest and least interesting period from the time of Aristotle (384 - 322 B.C.) to that David Hume (1711 - 1776) since Aristotle and many other prepositivists "took the stance of passive observer" (p. 18). When scientists began to try ideas and see if they worked, when they became active observers, science passed into the positivist period as Lincoln and Guba argue.

Positivism can be defined as a philosophy characterised by an extremely positive evaluation of science and scientific method which emphasises there is a common reality that serve for explanation and prediction. As a philosophy, the movement began early in the $19^{\text {th }}$ century and had its major impact on scientific method. Maykut and Morehouse (1994) point out that positivism was first introduced by the French philosopher Agusto Comte in 1830s. According to Comte positivism was associated with science and observable facts and it is assumed that methods of natural science could be applied in social science. Lincoln and Guba (1985), on the other hand, suggested that positivism began with the publication of John Stuart Mill's 'A System of Logic' in 1843 claming that the social and natural sciences have identical aims and methodology.

At the heart of these assumptions of positivism there is a denial that theory could represent hidden realities. Mary Hesse, cited in Lincoln and Guba (1985) criticises positivism in the three most important assumptions, which are naïve realism, belief in a universal scientific language, and a correspondence theory of truth. According to these assumptions, there is an external world which, can be described in scientific language and there is one-to-one relation to facts that the scientist can capture the external facts of the world. In similar to these assumptions Cohen and Manion (1994), pointed out four assumptions of determinism; events have causes and that they are explicable in terms of previous circumstances; the second is empiricism, which claims that reliable knowledge can only originate and verifiable by observations; the third one is parsimony which requires the phenomena should be explained in the most economical way and the last one is the idea of generality.

Beginning in the second half of the $20^{\text {th }}$ century, the revolt against positivism occurred on a broad front. It has been a reaction against the world picture projected by science's mechanistic and reductionist view of nature related to the assumptions above which excludes notions of choice, freedom and individuality as Cohen and Manion (1984) argue. Lincoln and Guba (1985), however, state that postpositivism - qualitative paradigm- is rather a reaction to the failings of positivism. Maykut and Morehouse (1994) acknowledge that Freud and Piaget studied neurotic women and children, sociologists at the Chicago School of Sociology studied street gangs. Yet, until 1960s educational researchers did not recognised qualitative paradigm.

Qualitative researchers are called journalists or soft scientists and their work is regarded unscientific, exploratory, or personal and full of bias (Denzin and Lincoln, 1998a). As criticisms grew qualitative researchers stressed the socially constructed nature of reality, the intimate relationship between the researcher and what is studied. William Blake, English poet, stated his perception of universe not as a mechanism, but as a living organism. Kierkegaard whose work was to originate the movement of Existentialism was concerned with individuals and their need to fulfil themselves (Cohen and Manion, 1994). Qualitative researchers expressed the need for searching answers to questions how social experience is created and given meaning in contrast with the quantitative researchers who emphasised the measurement and analysis of causal relationships between variables, not processes (Denzin and Lincoln, 1988; Yıldırım and Şimşek, 2008).

In this context I think that it is useful to give Tom Harre's comparison of positivism with the 'qualitative paradigm' in Lincoln and Guba (1985):

"Where positivism is concerned with surface events or appearances, the new paradigm takes a deeper look. Where positivism is atomistic, the new paradigm is structural. Where positivism establishes meaning operationally, the new paradigm establishes meaning inferentially. Where positivism sees its central purpose to be prediction, the new paradigm is concerned with understanding. Finally, where positivism is deterministic and bent on certainty, the new paradigm is probabilistic and speculative" (p.30).

Deriving from this comparative definition, Sherman and Webb (1988) state that qualitative implies a direct concern with experience as it is 'lived' or 'felt' or 'undergone'. In contrast, quantitative research is indirect, treats experiences as similar 'adding', 'multiplying' or 'quantifying' them. Qualitative research, unlike quantitative, has the aim of understanding experience as nearly as possible as its participants experience it. In Sherman and Webb (1988) it is stated that Dewey (early 1900s) did not take a side in the debates over quantitative versus qualitative inquiry. Rather he argues that each mode has its own function and unless qualities are considered, inquiry will be isolated and mechanical. Thus, experiences are wholes and must be treated as wholes.

Qualitative inquiry, in the light of these issues, According to Edson, plays an important role in educational research in raising new questions, questioning assumptions and expanding more critical and intellectual dimensions of human 
thought (in Sherman and Webb, 1988). Related to this, Newman and Benz (1998) point out that in the 1960s society began to experience radical changes and education moved into a more complex social context in which the effectiveness of the positivists' tools began to be questioned as a result of introduction of qualitative paradigm.

\subsection{Nature of the Quantitative and Qualitative Paradigms}

After giving a brief general and historical background about the quantitative and qualitative paradigms, I would like to focus on the quite distinct nature of these paradigms. Quantitative research is based on a positivist position, whereas qualitative research is originated from a phenomenological position including areas such as ethnomethodology, symbolic interactionism, hermeneutic inquiry, grounded theory, naturalistic inquiry and ethnography (Maykut and Morehouse, 1994). According to Maykut and Morehouse (1994), phenomenological position sees the person "as having no existence apart from the world, and the world as having no existence apart from the person" (p. 3). Reese in Lincoln and Guba (1985) argues that positivist position is based on a positive evaluation of science and scientific method. Thus, positivism studies observable facts based on measurable variables. Yet, in Locke et al. (1993) it is suggested that in qualitative research the focus is on the perceptions and experiences of the participants. In that sense, they regard this as a relativistic view of the world in which there is no search for absolute 'truth' that functions as a cause and effect relationship.

As Denzin and Lincoln (1998a) state quantitative research is seldom able to capture the subjects' perspective because of relying on more remote, inferential empirical materials. Qualitative research on the other hand, sees this world in action; findings embedded in it. As compatible with Denzin and Lincoln, Cohen and Manion (1994) point out that understanding of individuals' interpretations of the world has to come from the inside, not the outside. Qualitative inquiry, unlike quantitative inquiry, depends on subject-subject relation, not a subject-object relation; as a means of dealing with the direct experience of people in particular scientific context. This means as Denzin and Lincoln (1998a) argue; qualitative researchers study things in their natural settings trying to make sense of and interpret in terms of people's point of view, whereas quantitative researchers are less concerned with such things and they seldom study the phenomena directly.

Walker in Walker (1985) states that "a central tenet of the positivist is the view that the study of society and human behaviour should be scientific in the mode of the natural sciences" (p. 9). Shimahara cited in Sherman and Webb (1988) discuss that human behaviour and experience are shaped in context and they cannot be understood adequately if isolated from their contexts. Shimahara calls such isolation 'context stripping'; which is a key feature of science. In the same book Edson (1988) also states that qualitative research is context specific unlike quantitative research; which examine phenomena in context-free or context-independent ways. As Morse et al. (2008) argue qualitative research is context dependent rather than prescribed therefore qualitative researchers constantly deal with the unexpected. Thus, qualitative researchers focus on natural settings and qualitative research is sometimes called 'naturalistic inquiry' (Lincoln and Guba, 1985).

Another hallmark of qualitative approach is that experience is studied as a whole, or holistically. Both Giarelli and Chambliss (1988) and Shimahara believe that some elements in experience cannot be measured quantitatively (in Sherman and Webb, 1988). Another feature of qualitative research is the notion of 'subjectivity', which I think has a direct link with the emphasis of 'context' and 'wholeness of experience' as discussed earlier. However, the notion of 'subjectivity' puts qualitative paradigm in a very vulnerable position. Maykut and Morehouse (1994) use the term 'perspectival' instead, arguing that the term 'subjective' carries too much misleading connotations. The qualitative paradigm emphasises the importance of subjective experience of individuals unlike the quantitative paradigm. In this sense, qualitative research is not a search for knowledge for knowledge sake, but a search for the significance of knowledge.

In the light of this, it would be true to say that qualitative researchers reject the predetermined and/or accepted concepts and theories, they rather prefer a theory emerging from the context which is not universal but contextual. This approach can be called as 'inductive reasoning', which would enable to form a hypotheses and eventually a generalisation but not a deduction of unknown parts from the known. However, quantitative researchers prefer to use 'deductive reasoning', which is based on the idea of understanding particular and/or unknown parts through general and/or known parts (Cohen and Manion, 1994). Creswell (1994), also argues that quantitative inquiry is based on testing and measuring a theory through statistical procedures in order to understand whether the generalisation of existing theory is working. As a result 'inductive reasoning' is open and unstructured while 'deductive reasoning' is predictive and rather closed.

I would like to discuss the concepts of 'Grounded Theory' and 'Symbolic Interactionism', which are closely interwoven with the phenomenological approach and yet which are contrary to the positivist understanding of the world. In phenomenological approach it is argued in Cohen and Manion (1994) that "we must use ourselves as a key 
to our understanding of others and conversely, our understanding of others as a way of finding out about ourselves" (p. 27). So, the reality is socially constructed and grounded in people's experience.

Strauss and Corbin (1990) define Grounded Theory approach as a "qualitative research method uses a systematic set of procedures to develop an inductively derived grounded theory about a phenomenon" (p. 24). Grounded Theory finds its roots in Symbolic Interactionism, which claims that people, interact with each other through meaningful symbols. In Sherman and Webb (1988), Hutchinson argues that the belief that meanings evolve over time through social interactions is contrary to the positivist approach since "positivist view the world as being 'out there' and for symbolic interactionist, the human reality is not simply 'out there' awaiting scientific study; instead, it is socially and symbolically constructed" (p. 124). Such an understanding is reflected in grounded theory research. For Strauss and Corbin (1990) the notions of discovery and creativity are so crucial to grounded theory and they require discovering the world as seen through the eyes of the participants, understanding behaviour, and the basic social processes or structures (see also Sherman and Webb, 1988; Bogdan and Biklen, 1992; Cohen and Manion, 1994; Maykut and Morehouse, 1994).

Denzin (1989) also points out that symbolic interactionism rests on the idea that "humans learn their basic symbols, their conception of self, and the definitions they attach to social objects through interaction with others" (p. 5). Since interactionists regard human interaction as their basic source of data grounded theory serves well in defining ever-changing objects, redefinitions or reformulations, refocus or relocations and clarifying existing theory. If little is known about a topic and few adequate theories exist to explain the given situation, grounded theory is especially useful (see Denzin 1989, Sherman and Webb, 1988). These two approaches (grounded theory and symbolic interactionism) and the other approaches like hermeneutic inquiry, naturalistic inquiry, and ethnography are closely interrelated to each other and should not be seen as isolated but complementary concepts in relation to qualitative paradigm. They also would be useful in terms of positivist paradigm since they rather constitute a distinct nature; which would lead us to understand from quite opposite perspectives.

\subsection{The Assumptions of Quantitative and Qualitative Paradigms}

The relationship between paradigms, postulates and assumptions is a complex and interrelated one. Maykut and Morehouse (1994) define a paradigm as "a set of overarching and interconnected assumptions about the nature of reality" (p. 4). They also state that "postulates are the individual assumptions that are stipulated to be true and a set of postulates make up a paradigm" (p. 4). Lincoln and Guba (1985), on the other hand, use the term 'axiom' as synonymous with assumptions and they define axioms as "the set of undemonstrated (and undemonstratable) basic beliefs accepted by convention or established by practice as the building blocks of some conceptual or theoretical structure or system" (p. 33).

Maykut and Morehouse identify six postulates -based on Lincoln and Guba- and Lincoln and Guba state five axioms which, will be discussed briefly. Reflecting on readings I have done, I believe that the basic difference between positivist and phenomenological paradigms emerge from the different world views; the positivist paradigm, sees the world as simple or at least potentially simple as it can be examined properly and/or broken apart correctly. Whereas, the latter one sees the world as complex and interrelated. I think basically related postulates stem from these two distinct views and answers to these postulates are quite different in each paradigm.

When I am discussing the postulates I will draw on three basic references, which I think very useful, Lincoln and Guba (1985), Maykut and Morehouse (1994) and Creswell (1994) who share similar points except slight differences. Maykut and Morehouse (1994) argue that 'Ontological Assumptions' concern questions about the nature of reality; 'Epistemological Assumptions' concern the origins of knowledge and the relationship between the knower and the known; 'Axiological Assumptions' study the roles of values in understanding; 'Logic' deals with the possibility of generalisation and causal linkages between bits of information, and 'Teleological' questions try to find out what does research contribute to knowledge. Lincoln and Guba (1985) identify similar axioms except the 'research's contribution to knowledge'. In order to be clear I will give the identified assumptions/axioms in question form and then discuss them in terms of each paradigm.

Assumptions of the Research Paradigms:

i. How does the world work? (ontological)

ii. What is the relationship between the knower and the known? (epistemological)

iii. What role do values play in understanding the world? (axiological)

iv. Are causal linkages possible?

$\mathrm{v}$. What is the possibility of generalisation? 


\section{vi. What does research contribute to knowledge? (teleological)}

In terms of ontological assumptions, positivists believe that there is only one reality, which can be divided into independent variables and processes, which can be examined independently of the others. By carefully dividing and studying its parts, the whole can be understood (see Lincoln and Guba, 1985; Maykut and Morehouse, 1994). Creswell (1994) also argue that "the quantitative researcher views reality as 'objective', 'out there' independent of the researcher. Something can be measured objectively by using a questionnaire or an instrument" (p. 4). In contrast, according to Maykut and Morehouse (1994), qualitative researchers believe that there are multiple realities and "these realities are socio-psychological constructions forming an interconnected whole" (p. 13). Lincoln and Guba (1985) also state that multiple realities should be studied holistically in any given situation. Creswell (1994), points out that for the qualitative researcher, the only reality is that constructed by individuals. Thus, multiple realities exist involving the researcher, participants, and the reader or audience interpreting a study.

On the epistemological question, the positivists think that the knower can stand outside of what is to be known and the relationship between them is independent (see Lincoln and Guba, 1985; Maykut and Morehouse, 1994). Creswell (1994) argues that in quantitative approach the researcher remains distant and independent of that being researched in order to control for bias and be objective in assessing a situation. She or he continues that with qualitative stance and points out that in qualitative paradigm, unlike quantitative approach, researchers interact with those they study through the form of living with, observation, or actual collaboration.

This stance has implications for the axiological assumptions of the role of values in a research. The researchers' values are kept distant in a quantitative study through omitting statements about values from a written report and using impersonal language. Yet, for Creswell (1994), qualitative researcher admits the value-laden nature of the study, his/her own values and biases and the information gathered from the field. The language unlike quantitative one, can be personal and first person point of view. Lincoln and Guba (1985) argue that in qualitative (naturalist) paradigm, inquiry is value-bound in at least five ways; it is influenced by 'inquirer' values, by the choice of the 'paradigm' in the investigation of the problem, by the choice of the 'substantive theory' in the collection and analysis of data and in the interpretation of findings, by contextual values and by the nature of inquiry itself.

Another distinction is the possibility of causal linkages. In positivist paradigm, Maykut and Morehouse (1994) argue that "one event comes before another event and can be said to cause that event" (p. 12). Lincoln and Guba (1985) emphasise the importance of causality in the positivist paradigm. Unlike the quantitative paradigm, the qualitative views events shaping each other and multidirectional relations can be discovered in a mutual way (see Lincoln and Guba, 1985; Maykut and Morehouse, 1994).

On the issue of the possibility of generalisation, in Maykut and Morehouse (1984) quantitative researcher views explanations as they can be generalised from one time and place to other times and places. Thus, quantitative researchers eliminate all the aspects of the environment in order to apply its results to the possible number of subjects assuming that what is true at one time and place, under appropriate circumstances, would also be true at another time and place. The qualitative stance is different; for Maykut and Morehouse (1994) only tentative explanations for one time and place are possible, therefore understanding a phenomena with all its complexity is only possible within a particular situation and environment since qualitative inquiry is context-specific (see, Lincoln and Guba, 1985; Sherman and Webb, 1988; Denzin and Lincoln, 1998a). Sin (2010) also argues that qualitative research pursues diversity in meanings of complex phenomena in a particular context, therefore generalisability can be considered in terms of transferability, which is to what entend findings can be used or applied in other contexts. Maykut and Morehouse (1994), suggest the sixth assumption of 'research's contribution to knowledge'. They argue that positivists try to find out verification or proof of propositions, whereas; the phenomenologists search for discovery or uncovering propositions.

Creswell (1994), in addition to basic assumptions, identifies two different distinctions of 'rhetorica' and 'methodological' assumptions. The rhetorical assumptions deal with the rhetoric or language of the research. While a quantitative researcher chooses an impersonal and formal language, which is based on accepted words such as 'relationships', 'comparison'; qualitative researcher uses a personal and informal language based on definitions that emerged from the study such as; 'understanding', 'discovery' and 'meaning' which are quite distinct from the traditional research language. This assumption of qualitative paradigm, I think, is highly related to 'subjective' or 'personal' nature of it which was discussed earlier (see Cohen and Manion, 1994; Maykut and Morehouse, 1994; Denzin and Lincoln, 1998a). In terms of methodological assumption, for Creswell (1994) the entire process of a study differs in each paradigm. Basically in quantitative methodology a deductive form of logic is used; whereas, in qualitative one inductive logic is essential as discussed before (see Cohen and Manion, 1994). 


\section{Criticisms of Quantitative and Qualitative Paradigms}

\subsection{Quantitative Paradigm}

I think, after discussing the unique nature of paradigms and assumptions; it is not difficult to guess the criticisms of positivist paradigm. Cohen and Manion (1994) argue that:

"Positivist approach fails to take account of our unique ability to interpret our experiences and represent them to ourselves. We can, and do construct theories about ourselves and our world; moreover, we act on these theories. In failing to recognise this, positivist social science is said to ignore the profound differences between itself and the natural sciences" (p. 25).

Since positivist paradigm stands in a subject-object relation it deals with a pre-interpreted world, thus; the findings of positivistic social science are generally banal and trivial that they have little relation to those whom they are supposed to reach (teachers, social workers etc.). Positivists generally restrict, simplify, and control variables with their scientific experimentation in the laboratory. Lincoln and Guba (1985) identify five aspects of criticism to positivist stance. They argue that positivism excludes the 'context of discovery' which deals with the origin of scientific theories but focuses on the 'context of justification' which deals with testing theories. Secondly, positivism is highly associated with deductive reasoning, which does not give enough space to unique situation. It also refuses to deal with meanings or implications due to its deterministic and reductionist nature. This nature mostly stems from its emphasis on ethic research which is researcher-determined carrying an outside perspective instead of an inside perspective. Positivism get great amount of criticism regarding its assumptions discussed earlier since they are difficult to maintain.

\subsection{Qualitative Paradigm}

Qualitative paradigm also gets criticisms mainly because of lack of validity, reliability and objectivity. Denzin and Lincoln in Denzin and Lincoln (1998b) point out that conventional positivist approach applies four criteria to disciplined inquiry: internal validity, the degree the findings correctly map the phenomenon; external validity, the degree that findings can be generalised to other settings; reliability, the extent to which findings can be replicated, or reproduced by another inquirer; and objectivity, the extent to which findings are free from bias. They argue that in qualitative stance objective reality can never be captured. Reflexivity, however, deals with issues of researcher objectivity, as Lincoln and Guba (1985) argue this issue is not related with whether the researcher has influenced the research process, but it is concerned with how it is addressed. Therefore, the researcher recognises his or her own preconceptions and takes deliberate actions to minimize the potential influence through careful documantation, reliability check and triangulation (see Ekiz, 2003; Sin, 2010). As Morse (2006) states, reliability, however, is not done for re-producing prior findings, but to revisit or re-examine the findings as qualitative evidence is expected to change over time. Goodwin and Goodwin (1996) argue that reliability and validity are also key concerns in qualitative research. However, there are some general differences between the two research traditions, in theoretical and operational ways. They state that in qualitative research, data collection is an integral part of the design and analysis; whereas, in quantitative research studies, measurement of the variables is done with independent instruments. Therefore, the discussion of validity and reliability in qualitative research is not focused on measures but on concerns of the design or entire study.

In terms of methodology, Silverman (1993) argues that quantitative researchers regard observation as a not very 'reliable' method since different observers may record different observations. In qualitative approach this view is appreciated (see axiological assumption) and the observational method has often been used to understand another culture or context. Quantitative researchers analyse written material through 'content analysis' and categories in order to produce reliable evidence. Yet, in qualitative research the aim is to understand the participants' categories and the reliability of the analysis is less frequently addressed. Similarly, a central methodological issue for quantitative researchers is the reliability of the interview schedule and the objectivity therefore 'fixed-choice' questions are preferred which lend themselves to tabulations. Whereas, 'authenticity' rather than reliability is generally the issue in qualitative research so 'open-ended' questions are generally chosen.

Walker in Walker (1985) also argues that since qualitative techniques are not concerned with measurement they tend to be less structured than quantitative ones and therefore they can be more responsive to the needs of respondents and to the nature of the subject matter. In terms of analysis he points out that qualitative data is more interpretive, creative and personal than in quantitative analysis which does not necessarily mean it is less systematic and careful. Miles and Huberman (1994), despite of seeing some problems with qualitative data analysis, they agree on the issue that "with qualitative data, one can preserve chronological flow, assess local causality, and derive fruitful explanations" (p. 22). They also state that qualitative findings are more convincing to a reader than pages of numbers. 


\section{Linking Qualitative and Quantitative Approaches}

\subsection{The Rationale of Linking Approaches}

In linking approaches, after discussing the issues about qualitative and quantitative research paradigm, I will now discuss the idea and possibility of linking them. Goodwin and Goodwin (1996) argue that each research type has unique strengths and limitations that can promote their combined use. Each research is associated with certain methods of data collection; quantitative research is associated with surveys, structured interviewing, questionnaires and observation, content analysis and the statistics. Whereas, qualitative research is associated with participant observations, semi and unstructured interviewing, case studies, discourse analysis and the like (see Cohen and Manion, 1994).

Quantitative research, as Brannen argues in Brannen (1992), is associated with the process of enumerative induction which aims to discover how many and what kinds of people in the general have a particular characteristic in the sample population. Yet, qualitative research is associated with the analytic induction in which the concepts and categories are considered instead of the incidence and frequency. In this sense linking them may help us to understand the general picture. Locke et al. (1993) argue that combined studies have made important contributions to programme evaluation, organisational studies and the like. For Strauss and Corbin (1990) another reason for linking data is the nature of the research problem. Some areas of study lend themselves more to qualitative types of research such as the nature of people's experiences related to a phenomenon about which little is yet known.

Cohen and Manion (1994) point out that by linking data the weaknesses of each methods can be strengthened concerning the given problem. They also mention that combined approach gives a more holistic view of educational outcomes, a fuller and more realistic view in terms of comparative basis and broader perspectives and it is also appropriate when different methods of teaching are to be evaluated. Both Denzin (1989) and Brannen (1992) argue that the validity of findings and the degree of confidence will be enhanced by the use of multiple data collection.

Bryman in Brannen (1992) mentions some advantages of combined research. Bryman suggests that, in a similar fashion with Goodwin and Goodwin (1996), some groups may be more receptive to a qualitative than to a quantitative component or vice versa so that the broad conduct of research is easier. He also argues that combined research may smooth the research sites. On the other hand, like Bogdan and Biklen (1992) who note that, especially for novice researchers, combined design could be a headache and there is a danger that the research would not meet the criteria in either approach, Bryman also mentions that combined research is by no means unproblematic. He argues that since quantitative and qualitative researchers have highly contrasting strengths and weaknesses, it is highly questionable whether they are concerning the same things even when they are examining similar issues and second difficulty is the possibility of conflict in the research evidence.

Newman and Benz (1998) view the issue of combined research rather holistically. They suggest the 'qualitative-quantitative interactive continuum model' (p. 23) which, suggests that quantitative and qualitative research are in fact a continuum. They argue that the qualitative research is concerned with theory building; on the other hand, the quantitative research deals with theory testing. Therefore, this continuum is interactive and should be studied holistically.

\subsection{Ways of Linking Data}

The term 'triangulation', as Bloor (1997) points out in Miller and Dingwall, has become overloaded with meanings and abused by uncritical use. It is treated as a validation exercise because it is assumed that replication of the findings by different methods decreases the measurement biases. Both Denzin (1989) and Brannen (1992), drawing from Denzin, refer to four basic types of triangulation; data, investigator, theory and methodological which may be between-methods or within-method.

As they argue a within-method approach involves the use of method on different occasions, while between-methods requires using different methods in relation to the some object of study which has become the target of 'validity assurance' issue mentioned above. Multiple investigator research is carried out by partnerships or teams rather than by one individual. In this method research organisation can be a problematic issue since it involves different individuals therefore different perspectives. Multiple data sets require the application of different methods or the use of the same method at different times or with different sources. Data may be collected from a range of different people rather than one individual or at different points in time and in a variety of contexts, situations and settings. Multiple theories may employ a number of possible theories and hypotheses about the research problem driving from initial data analysis, together with insights from the research process itself. Alternatively, an examination of prior research may lead the researcher to test a number of possible competing hypotheses on his or her findings.

Brannen in Brannen (1992), drawing on Bryman (1988) identifies three main ways of combining methods: 
qualitative work as a facilitator of quantitative work; where qualitative methods play a subsidiary role in a project. They may act as a development and piloting of research instruments. Essentially, qualitative method may ease the interpretation and clarification of quantitative data. Secondly, quantitative work as a facilitator of qualitative work; where they provide quantified background, which would help to contextualise small-scale intensive studies. Quantitative methods may also be used to test hypotheses and a basis for the sampling of cases and comparison groups resulted from the qualitative work. In the third way both approaches are given equal emphasis where combined methods may result in two separate but linked studies which are distinct from one another at all stages of the research process or the methods are integrated in the one study in the fieldwork phase or in the analysis or writing-up stage. She also argues that the factor of the importance given to each approach and the time ordering of methods-methods carried out consecutively or simultaneously- are important in terms of structure of the combined design.

Bryman in Brannen (1992) and his previous work (1988) suggests ways for combining data apart from the ones mentioned above. He states that the findings from one type of study can be checked against the findings deriving from the other type in order to enhance the validity of findings. He also argues that 'structural' features of quantitative research and 'processual' aspects of qualitative studies can be brought together to strengthen the study. Another way is to combine researcher's concerns stemming from quantitative research and subject's perspectives deriving from qualitative research in a single study. As Bryman argues $(1988,1992)$ employing both quantitative and qualitative research may provide a means of bridging the macro-micro gulf since quantitative research often studies large-scale structural features of social life, while qualitative research represents small-scale, behavioural aspects. Another use for combined research is to employ quantitative and qualitative research in different stages of a longitudinal study. He also argues that hybrids, which have elements of both research traditions, can be used.

Bullock et al. in Brannen (1992) suggests four models of linking quantitative and qualitative approaches for social policy research. The first model is where the quantitative findings are illustrated by qualitative case studies. Second way is to use qualitative results to explain the findings of quantitative research. The third model is the use of qualitative evidence to produce hypotheses, which can be tested quantitatively. The last model requires using qualitative studies to produce typologies, which would improve the understanding of factors, found out through quantitative evidence.

Bryman (1988) also mentions a rather different view, the epistemological view of combining two research paradigms. He argues that this version does not admit a blending of quantitative and qualitative research since the two traditions represent highly contrasting views about how social reality should be studied. The technical version of the debate enables the marriage of the two paradigms since it recognises the strengths and weaknesses of the two approaches as methods of data collection. He notes that the lack of a definitive link between epistemological positions and methods arise the questions concerning whether there is a link between epistemology and method of data collection or there ought to be such a bond. If the answer is 'yes' the epistemological argument runs into difficulties since this does not approve the linking of data. However, he concludes in technical stance; more complete accounts of social reality can be captured through combined approach.

Creswell (1994) also considers similar questions of should paradigms be linked with methods? Or the paradigms must be linked with research methods. He argues that several schools of thinking arose in this debate. The 'purists' say the paradigms and methods should not be mixed; the 'situationalists' think that certain methods are appropriate for specific situations; and the 'pragmatists' attempt to integrate methods in a single study. Creswell, after giving this background, suggests three models of combined designs. The first model is two-phase design approach, in which the researcher employs both a qualitative phase of the study and a separate quantitative phase of the study. In this approach the two paradigms are clearly separate which would be advantageous in order to see the underlying paradigms behind each phase and disadvantageous since the reader may not see the connection between the two phases. He calls the second model the dominant-less dominant design reminding of Bryman's facilitator models discussed earlier, which would get reactions from the purists. The third model is the mixed-methodology design, which represents the highest degree of mixing paradigms at all or many methodological steps in the design. This approach as Creswell argues, adds complexity to design and requires a sophisticated knowledge of both quantitative and qualitative paradigms, which would cause difficulties for both researcher and readers but surely best mirrors the research process in wider perspective.

\section{Conclusion and Implications}

At the end of my article I hope that this article would contribute to especially novice researchers' knowledge and understanding of quantitative and qualitative paradigms, their nature, advantages, disadvantages, assumptions, criticisms, and the possibility of linking two paradigms. I know that I have just touched upon a very complex issue 
which needs to be deepened for future studies. I have also realised that I do subscribe to qualitative paradigm and its methodology more than I do to quantitative paradigm. However, I do believe that one should not deny any of them since they both aim to generate knowledge (Goodwin and Goodwin, 1994) and work for a better understanding of humanity; for us. They only use some different methodology and approach based on different theories and understandings. As Howe (2008) argues quantitative and qualitative methods can be compatible in spite of the fact that their epistomological approaches are quite distinctive. Therefore any good researcher at least needs have a good understanding and appreciation for each research paradigm whether he/she uses it or not.

It should be also known that some topics would best suit only one of the research paradigm because of their nature, time, place, practicality or any particular reason. In some cases a researcher might use a combined methodology due to some specific reasons as discussed earlier. I think as a result when combining data as Patton (1987) argues; it is useful to gather data within the larger context of evaluation. Patton identifies five questions for data collection options and strategies, which are I think crucially important: Who is the information for and who will use the findings of the evaluation? What kinds of information are needed? How is the information to be used? For what purposes is evaluation being done? When is the information needed?, What resources are available to conduct the evaluation? Answer to these questions, I do believe, will determine the data choice and appropriate evaluation and combination. The most important issue is to choose the most appropriate research design or combinations of methodology for the research question or problem. So, I think, it is not very reasonable to stick only one of the research paradigm even though one may have a preference. But of course sometimes the context, timing and place or any particular reason/s - may force one to employ a particular design/s (Bell, 1993). So one has to take into account these factors when deciding on methodology as well.

\section{References}

Bell, J. (1993). Doing your research project: a guide for first time researchers in education and social science. Buckingham: Open University Press.

Bloor, M. (1997). Techniques of validation in qualitative research: a critical commentary. In G. Miller \& R. Dingwall (Eds.) Context and method in qualitative research (pp. 37-50). London: Sage Publications. http://dx.doi.org/10.4135/9781849208758.n3

Bogdan, R. C., \& Biklen, S. K. (1992). Qualitative research for education: an introduction to theory of methods. London: Allyn and Bacon.

Brannen, J. (1992). Combining qualitative and quantitative approaches: an overview. In J. Brannen (Ed.) Mixing methods: qualitative and quantitative research (pp. 3-38). Aldershot: Ashgate Publications.

Bryman, A. (1988). Quantity and quality in social research. London: Routledge. http://dx.doi.org/10.4324/9780203410028

Bryman, A. (1992). Qualitative and quantitative research: further reflections on their integration. In J. Brannen (Ed.) Mixing methods: qualitative and quantitative research (pp. 57-78). Aldershot: Ashgate Publications.

Bullock, R. et al. (1992). The relationships between quantitative and qualitative approaches in social policy research in J. Brannen (Ed.) Mixing methods: qualitative and quantitative research (pp. 81-100). Aldershot: Ashgate Publications.

Cohen, L., \& Manion, L. (1994). Research methods in education. London: Routledge.

Creswell, J. W. (1994). Research design: qualitative and quantitative approaches. London: Sage Publications.

Denzin, N. K. (1989). The research act: a theoretical introduction to sociological methods. New Jersey: Prentice-Hall.

Denzin, N. K., \& Lincoln, Y. S. (1998a). Entering the field of qualitative research. In N.K. Denzin \& Y.S. Lincoln (Eds.) The landscape of qualitative research: theories and issues (pp. 1-34). London: Sage Publications.

Denzin, N. K., \& Lincoln, Y. S. (1998b). Major paradigms and perspectives. In N.K. Denzin \& Y.S. Lincoln (Eds.) The landscape of qualitative research: theories and issues (pp. 185-193). London: Sage Publications.

Edson, C. H. (1988). Our past and present: historical inquiry. In R.R. Sherman \& R.B. Webb (Eds.) Qualitative research in education: focus and methods (pp. 44-58). London: The Falmer Press.

Ekiz, D. (2003). Eğitimde araştırma yöntem ve metotlarına girişs: nitel, nicel ve eleştirel kuram metodolojileri (Introduction to research methodology: qualitative, quantitative and critical methodology). Ankara: Anı Publications. 
Giarelli, J. M., \& Chambliss, J. J. (1988). Philosophy of education as qualitative inquiry in R.R. Sherman \& R.B. Webb (Eds.) Qualitative research in education: focus and methods (pp. 30-43). London: The Falmer Press.

Goodwin, W. L., \& Goodwin, L. D. (1996). Understanding quantitative and qualitative research in early childhood education. London: Teachers College Press.

Howe, K. R. (2008). Isolating science from the humanities. In N.K. Denzin \& M.D. Giardina (Eds.) Qualitative inquiry and the politics of evidence (pp. 97-118). Walnut Creek, California: Left Coast Press inc.

Lincoln, Y. S., \& Guba, E. G. (1985). Naturalistic inquiry. London: Sage.

Locke, L.F. et al. (1993). Preparation of proposals for qualitative research: different assumptions in proposal that work: a guide for planning dissertations and grant proposals. London: Sage Publications.

Maykut, P., \& Morehouse, R. (1994). Beginning qualitative research: a philosophical and practical guide. London: Falmer Press.

Miles, M. B., \& Huberman, A. M. (1994). Qualitative data analysis: an expanded sourcebook. London: Sage Publications.

Morse, J. (2006). Insight, inference, evidence, and verification: creating a legitimate discipline. International Journal of Qualitative Methods, 5(1), 1-7. [Online] Available: http://ejournals.library.ualberta.ca/index.php/IJQM/article/view/4412/3531

Morse, J. M. et al. (2008). Qualitative researchers' conceptualization of the risk inherent in qualitative interviews. International Review of Qualitative Research, 1(2), 195-215. [Online] Available: http://www.lcoastpress.com/journal_issue.php?id=112

Newman, I., \& Benz, C. R. (1998). Qualitative-quantitative research methodology: exploring the interactive continuum. Carbondale, IL: Southern Illinois University Press.

Patton, M. Q. (1987). How to use qualitative methods in evaluation. California: Sage Publications.

Silverman, D. (1993). Interpreting qualitative data: methods for analysing talk, text and interaction. London: Sage Publications.

Sin, S. (2010). Considerations of quality in phenomenographic research. International Journal of Qualitative Methods, 9(4), 305-319. [Online] Available: http://ejournals.library.ualberta.ca/index.php/IJQM/article/view/6336

Strauss, A., \& Corbin, J. (1990). Basics of qualitative research: grounded theory procedures and techniques. London: Sage Publications.

Sherman, R. R., \& Webb, R. B. (1988). Qualitative research in education: a focus. In R.R. Sherman \& R.B. Webb (Eds.) Qualitative research in education: focus and methods (pp. 2-21). London: The Falmer Press.

Walker, R. (1985). An introduction to applied qualitative research. In R. Walker (Ed.) Applied qualitative research (pp. 3-26), Aldershot: Gower Publications.

Yıldırım, A., \& Şimşek, H. (2008). Sosyal bilimlerde nitel araştırma yöntemleri (Qualitative methods in social sciences). Ankara: Seçkin Publications. 